\title{
UNDERSTANDING CRITICAL CONCEPTS IN ENGAGED RESEARCH: THE CASE OF A RURAL HEALTH DEVELOPMENT PROJECT IN SOUTH AFRICA
}

\author{
Theodore Duxbury ${ }^{1,3}$, Sharli Anne Paphitis ${ }^{2,3}$, Joana Bezerra ${ }^{2,3}$ and Roman Tandlich ${ }^{1,3}$ \\ ${ }^{1}$ Faculty of Pharmacy, Makhanda, South Africa. theoduxbury@gmail.com; r.tandlich@ru.ac.za \\ ${ }^{2}$ Community Engagment, Makhanda, South Africa.s.paphitis@ru.ac.za; J.carlosbezerra@ru.ac.za
}

${ }^{3}$ Rhodes University

\begin{abstract}
Inadequate health coverage to rural areas is exacerbated by persisting socio-historical and economic barriers to rural health development, i.e. social and epistemic injustices such as poverty, racism, lack of education, and the effects of apartheid. Following this, the analysis of community health variables requires us to deploy complex conceptual models in our research approaches. In the case of rural health development presented in this chapter, we propose that an engaged research approach, underpinned by a complex conceptual model, is required to both properly understand and address rural health. Through an engaged research project pharmacists and fellow healthcare practitioners can understand the variables that determine community health and it can thereafter be harnessed and adapted for health development. This chapter promotes the integration of engaged research concepts, asset-based community development, culture and the transformative paradigm, epistemic justice, health promotion, and health literacy in developing rural health within a South African context.
\end{abstract}

Keywords: Engaged Research, Epistemic Justice, Transformative Paradigm, Rural Health Development, Culture, Asset-Based Community Development.

\section{INTRODUCTION AND CONTEXT}

Everyone has the right to the highest attainable standard of health (WHO, 2015b). As part of a comprehensive approach to health and human rights on both national and regional levels, the World Health Organization (WHO) has committed itself to strengthening the incorporation of human rights into healthcare systems and policies. This is being done through capacity building within the $\mathrm{WHO}$ and its Member States through advocacy and through advancing the right to health in international law and international developmental processes (PAHO WHO, 2019; Türmen et al., 2001). Low- and middle-income countries (LMICs) such as South Africa, however, still encounter great challenges to this vital human right (Humanium, 2016). The vulnerable and marginalized populations of these countries predominantly experience the demoralizing effects of both communicable and non-communicable diseases (NCDs), with major health and developmental consequences (WHO, 2016a). Inadequate health coverage to rural areas, including remote rural game reserve villages situated on protected and private conservation lands, results in reduced access to healthcare. Despite increases in healthcare facilities in remote rural areas, significant barriers to health development remain such as culture, affordability, mobility, travel costs, literacy, and the quality of healthcare, 
amongst others. Health inequalities within South Africa (SA) remain robust despite restorative efforts of the post-apartheid government, and marginalized families are often unable to obtain even the most basic healthcare.

\section{HEALTH INEQUALITIES AND THE SOCIAL DETERMINANTS OF HEALTH IN SOUTH AFRICA}

Socio-economic factors such as lack of income, mobility and developmental opportunities experienced by major segments of society, especially in low- and middle-income countries, have significant implications for health and economic development (International Monetary Fund, 2015). Healthy populations live long, are more productive, and can contribute to economic growth more effectively (WHO, 2015b). Unfortunately, lower socio-economic populations tend to have limited access to health information and health care services and thus experience the worst health when compared to those from more developed countries (Peters et al., 2008). Health inequalities contribute to maternal and infant mortality rates (WHO, 2015b), lower life-expectancy at birth, and slow economic development (World Economic Forum, 2016). Globally, marginalized families are often unable to obtain even the most basic health care, resulting in $70 \%$ of the global mortalities of children under five. Children in developing countries are also ten times more likely to die before the age of five than those in developed countries (WHO, 2011). Socio-economic factors, income, and income distribution are thus considered critical social determinants of health. Such socioeconomic inequalities concentrate political and decision-making powers in the hands of an elite minority. Hence, it is critical to establish the causal links between the cultural and socioeconomic factors, and their relation to poor health, i.e. infectious and non-communicable diseases, injuries, and accidents.

South Africa's economically active population accounted for only $35 \%$ of the total population in 2010 (Duxbury et al., 2016). The poorest 40\% of SA's population receive $41 \%$ of the country's health benefits while only contributing $6.28 \%$ of all the revenue spent on healthcare; and the richest $40 \%$ of the country pay for $87 \%$ of the healthcare provided in both private and public healthcare facilities (Armstrong et al., 2017). The South African government serves $80 \%$ of the population (8 in 10 people) with public healthcare services (WHO, 2015a). Forty-six percent of SA's population reside in rural communities and they are served by only $12 \%$ of SA's doctors and $19 \%$ of nurses. A lack of access to healthcare within SA, specifically within the Eastern Cape Province (EC), is further exacerbated by socio- 
economic status, disabilities, geographical location, mobility, cultural norms and practices, and patient perception of affordability and benefits of seeking healthcare (Frost et al., 2017; McLaren et al., 2013). The EC province constitutes 14\% of SA's population, with more than four million citizens residing in non-urban areas, previously neglected and marginalized by the Apartheid government (HSRC, 2012; Ubunye Foundation, 2018). The majority of the EC population are women (56\% of provincial population) and children (34\% of provincial population) as men migrate to other provinces to pursue economic opportunities. The Eastern Cape has unemployment rates as high as $37.4 \%$ as reported in 2019 , the highest in the country (Statistics SA, 2019).

The Sarah Baartman District, in the Eastern Cape, reported that $12.5 \%$ of individuals receive no income (The Department of Economic Development, 2017). Levels of inequality within the EC Sarah Baartman District and Makana Local Municipality remain high, with a GiniCoefficient of 0.73 and 0.615 , respectively (Makana Municipality, 2017). The EC Sarah Baartman District is the second highest percentage compared to other EC districts (The Department of Economic Development, 2017). Due to the employment scarcity and the modest wages received by farm and game reserve workers, villagers are mostly dependent on seasonal agriculture, government poverty alleviation initiatives, and social and child support grants. Socio-economic inequalities, in addition to lower levels of educational attainment, strain the EC healthcare system through facilitating elevated child and maternal mortalities, and communicable and non-communicable disease (NCD) prevalence. These health challenges require change to public service systems, procedures, attitudes, and behaviour. These complex healthcare issues also require both public and private sectors to play a role to equitably restore South Africa's unjust healthcare industry on both macro and micro levels.

The public health burden is exacerbated by low health literacy levels (Sheridan et al., 2011). Carstens et al. (2006) reported that the adults with the lowest literacy rates are those with the highest rates of morbidity and mortality. Marginal literacy is defined as having a literacy level equivalent to that of an eighth grade student (Pfizer et al., 2004). According to Carstens et al. (2006), South Africa has a readability level of basic health educational materials which corresponds to an individual with grade nine. More than $70 \%$ of the South African population only have marginal reading skills: $30 \%$ are functionally illiterate and $40 \%$ have limited skills (Carstens et al., 2006). If people are unable to have access to health literature or effectively comprehend health literature, they are less able to live healthy lifestyles and their right to 
health is compromised (South African Human Rights Commission, 2000). Compromised levels of education and literacy may also influence economic development (Rodrigo \& Andrés, 2010). It is therefore essential to understand and address the barriers to health literacy, as well as to investigate health literacy development facilitators in the South African context. As a result, we argue that the need for engaged research methodologies, which not only seek to determine barriers to public health but to address them with participants through the research process, are more necessary now than ever before.

\section{RURAL GAME RESERVE COMMUNITIES AND ENGAGED RESEARCH}

Game Reserves play an important environmental role in biodiversity conservation. Simultaneously, they play an economic role in the Eastern Cape Province by generating tourism revenue and employment for the local people living in villages near or within the reserves. However, the legacy of racial exclusion and exploitation in South Africa means that the reality for those living in villages on or near Game Reserves in the EC, one of the poorest provinces in South Africa, is that income still predominantly comes from social grants. In addition to this, the mobility of individuals residing in rural game reserve communities is often restricted because of the geographical location and socio-economic factors. Their particular geographic, as well as socio-historical, position has important health implications for communities in rural Game Reserves.

Currently, physical access to health care affects a multitude of health outcomes, especially for those patients residing in rural communities which are reliant on the continuity of healthcare services (Burger \& Christian, 2018; McIntyre \& Ataguba, 2014; McLaren et al., 2013; Tanser et al., 2006). This is specifically so for high-risk patients and for those with chronic diseases. Travel time and distance to health care facilities, have over the years been associated to decreased vaccination coverage (Acharya \& Cleland, 2000), decreased contraceptive use (Seiber \& Bertrand, 2002), increased adverse pregnancy outcomes (van den Broek et al., 2003), and increased maternal and infant mortality (van den Broek et al., 2003). Transport is vital for the continuity and provision of quality health care services to the rural communities and is therefore also considered a social determinant of health, within these contexts. Ensuring the transfer of patients back and forth between levels of health care is a crucial factor within the rural healthcare system. 
The availability and affordability of reliable transport services does not only affect access to healthcare services but also access to nutritious food resources to maintain good health and well-being (Matebeni, 2018). Individuals within these communities have seen a change in their lifestyle as it shifted from farming-based communities to hospitality-focused workers which impacted subsistence farming and severely affected the availability of fresh produce. The individuals most at risk are the elderly, the disabled, low-income families, and those with special health care needs. The geographical location, transport services and socio-economic background of patients therefore play an important role in ensuring community health and well-being. The socio-economic inequality experienced by those living within villages in or on Reserves has prompted the vision for collective agency by the Game Reserves and their local communities to build resilience, promote development, and preserve the natural resources in the Eastern Cape Province. Game Reserve staff and owners typically have disparate or even conflicting goals to those of the communities in their areas, but share a set of resources and ultimately rely on each other for future sustainability.

In light of all these challenges and injustices in public health, the context provides a suitable platform to introduce research methodologies rooted in epistemic justice. It is therefore critical, within this context, to understand and integrate engaged research concepts, where communities focus on realizing and strengthening the resources that they currently have and feel empowered by, instead of depending on external resources to sustainably support health development. Public health projects within these communities may fail to achieve their goals because they are based on top-down approaches. We, therefore, will take as a fundamental assumption that, for community members to stimulate change within their community, they must themselves be involved in the research or project developmental process from the beginning.

\section{ENGAGED RESEARCH CONCEPTS}

A focus on improving the equity and social status of women (Manhanzva et al., 2017), children, and the most disadvantaged, informs the agenda of the Sustainable Development Goals (SDGs), which build on the Millennium Development Goals (MDGs) and aim to be relevant worldwide (Results for Development Institute \& World Bank, 2014). While SDGs 3 and 5 are aimed at achieving universal health and well-being, both recognize that these cannot be achieved until the context specific health challenges are understood and realized. To achieve the SDGs, greater investment in disease prevention and health systems 
strengthening is required. The current public health context within South Africa, as outlined within the 'Introduction and Context' section of this chapter, supports a growing need to reform health systems through finding ways of doing more with existing resources. A suitable approach could be through harnessing innovative participatory, culturally appropriate, assetbased community health development strategies. The concepts within this chapter - engaged research, culture and the transformative paradigm, epistemic justice, health promotion, and health literacy - will therefore highlight the possibility of integrating such qualitative research methodologies within the South African context.

\section{ENGAGED RESEARCH}

Community based participatory research (CBPR) allows healthcare professionals to discover new ways to study and address complex health and social issues to encourage social change (Mairhofer, 2015; WHO, 2013). Participating in a CBPR project, the community can take greater responsibility for their own development, and, most importantly, shift their assumptions about what they can achieve on their own, without assistance from the government or external bodies (Cundill et al., 2014). In this way, participants become codevelopers in the CBPR to benefit their community, based on their own culture and understanding. CBPR has been proven to be a successful approach to rural health development within South Africa, as it plays a key role in identifying community needs and assets. CBPR also aided researchers in the negotiation of a mutual agenda between communities and researchers (Lazerus et al., 2014; Mosavel et al., 2005). This is a suitable concept to stimulate community empowerment and promote health within the South African context, where communities are located in remote rural villages, situated on protected land with limited-to-no access to healthcare services. An engaged research project draws on the principles and practices of community based participatory research, as follows.

\section{COMMUNITY BASED PARTICIPATORY RESEARCH PRINCIPLES}

There are two crucial CBPR principles identified by Israel and her colleagues (Israel et al., 1998). Firstly, the concept of community is an aspect of collective and individual identity and is central to community-based research. Units of identity can represent membership in a family, a friendship network, geographic neighbourhood, etc. and these are all socially structured dimensions of identity, created and recreated through social interactions. Secondly, to build on strengths and resources within the community, Israel and her colleagues (Israel et al., 1998) point out that, to perform a CBPR project, the researcher can 
seek to identify and build on the strengths, resources, and relationships that exist within communities of identity. By identifying and executing these factors, researchers will be able to address their communal health concerns. CBPR may seek to support or expand social structures and social processes that contribute to the ability of community members to work together to improve health. CBPR, therefore, achieves the balance between research and action (Mairhofer, 2015).

The CBPR approach can effectively be used to orientate community members towards a common goal and shared vision (Duxbury, 2019). The CBPR approach can empower individuals to be proactive in solving health challenges in their communities and create a sense of ownership and responsibility. Utilizing a CBPR approach can allow community members to have their skills and expertise acknowledged and valued during the research process. It provides a space where communities' knowledge is legitimately incorporated in the research process - rather than an extractivist approach.

\section{ASSET-BASED COMMUNITY DEVELOPMENT}

In South Africa, there is a long tradition of mobilizing community assets, particularly so during the Apartheid era (Abel, 2015; ANC, 1997). The Asset-Based Community Development $(A B C D)$ approach proposes an alternative to the needs-based approach (Boyd et al., 2008). The asset-based approach to community health development is a bottom-up approach which would ensure the inclusion of unique assets and strengths that the community may have, rather than focusing on deficits and health problems alone. The community assets referred to here may include talents, stories, innovations, knowledge, natural resources, physical assets, financial assets, cultural assets, rights, claims, and entitlements. Nel (2018) conducted a comparative study in South and Southern Africa and indicated that the ABCD approach is successful in reconnecting community members and in building trust. In this study, the ABCD approach also allowed community members to undergo consciousness changes from a poverty-influenced mind-set to members who created and piloted their own community projects much more sustainably and stimulated systemic change more effectively (Nel, 2018). This approach could, therefore, be aimed at motivating villagers in remote rural areas to focus in on the capacities and strengths which they already have and to build from there. ABCD can promote 'ownership' and more effective and sustainable rural health development efforts through empowering villagers to dedicate their time and talents to create the change they desire. The potential contribution of $A B C D$ approaches to health development is 
increasingly being recognized as it aims to identify and build on community assets, including the knowledge and skills of residents (van de Venter, 2016).

\section{CULTURE AND THE TRANSFORMATIVE PARADIGM}

Knowledge is socially and historically located within a complex cultural context (Murphy \& Ivinson, 2003). Respect for culture and awareness of power relations is therefore critical. The transformative paradigm's epistemological assumption informs a cyclical model of research that incorporates the establishment of partnerships between researchers and community members and building trust (Mertens, 2007). Culture is an essential part in the transformative paradigm and in health promotion contextualization. Thoraya Obaid stated in a United Nations Population Fund Report that, when we as engaged research practitioners, work towards developing projects within poor communities, "we need to be able to work with the people in the communities at their own level and we have to find common ground." It is further emphasized that "we may not believe in what they do or agree with what they do," but it is crucial "to have compassion and the commitment to understand them and to support them as they translate universal principles into their own codes, messages and ways of doing things. Human rights form our frame of reference" (UNFPA, 2004, p. 1). It is therefore essential that culturally sensitive approaches are used to promote human rights in ways that people can identify with and can internalize in the context of their own lives. This is critical as South Africa is a culturally diverse country, where culture influences health practices, beliefs, and patient health outcomes - specifically in rural areas.

Culture is an amalgamation of behaviours, values, attitudes, and beliefs that are shared by a group of people and passed along by communication and imitation from one generation to the next (Cleveland et al., 2016; Rogers et al., 2002). Differences in culture and corresponding behavioural preferences can be challenging to both researchers in academia and healthcare practitioners in demographically diverse contexts. Failure to acknowledge these differences can create communication barriers between the two parties involved (Li \& Karakowsky, 2001). To be able to promote health effectively, it is important to understand the community's perception of their health and illness, behaviors, and habits that influence community health, and how culture interacts with environment, economics, and politics to affect health. The cultural beliefs of a specific community influence their healthcare practices and local concepts about illness (Armenakis \& Kiefer, 2007). Through our experiences and observations as a pharmacy professional, this is especially appropriate in the Eastern Cape, 
which is a province where health practices are deeply rooted in cultural norms and practices. An example of this could be the integral role that alcohol and tobacco play in cultural rituals, which contributes to the epidemic rise in NCDs, as outlined in the "Introduction and Context" section of this chapter. The context of culture, therefore, provides greater depth and meaning to conceptualizing the health development needs of a specific population (Lie et al., 2012). In addition to this, culture also plays an essential role in the application of the transformative paradigm.

In contrast to the constructivist, pragmatic paradigms and the post-positivist approach, the transformative paradigm places emphasis on the dimensions of culture, power, privilege, and social justice. The transformative paradigm is specifically orientated towards marginalized communities. (D. Mertens (2009) states that "The transformative paradigm emerged in response to individuals who have been pushed to the societal margins throughout history and who are finding a means to bring their voices into the world of research" (p. 3).

The transformative paradigm therefore provides a framework for addressing inequality and injustice in society through using culturally competent, mixed method strategies to address the complexity of culturally significant settings which could provide the basis for social change. The transformative paradigm - under its four philosophical assumptions, these being ontological, epistemological, axiological and methodological - also places emphasis on the strengths that exist within communities which experience discrimination and oppression on the basis of their cultural values and experiences (Guba \& Lincoln, 1982, 2005; Mertens, 2005, 2007, 2010). Figure 1, illustrated below, suggests a conceptual model for the application of the transformative paradigm within a complex rural health development context in South Africa.

\section{AN EPISTEMIC JUSTICE APPROACH TO HEALTH DEVELOPMENT}

Social injustices such as poverty, racism, access to health care and education, and the effects of apartheid exacerbate epistemic injustices in South Africa (Anderson, 2012). Epistemic injustice is considered to involve the "most basic everyday practices: conveying knowledge to others by telling them and making sense of our own social experiences" (Fricker, 2007, p. 1). These injustices mostly occur when a person is insulted or wronged in their capacity as a knower. Fricker (2007) identified two types of fundamental discriminatory forms of epistemic injustice: testimonial and hermeneutical. Both are facilitated through 
credibility discounting and epistemic marginalization, which are influenced by hidden prejudices - an unconscious or preconscious cognitive bias. Testimonial injustices occur when a hearer discounts the credibility of a person's testimony due to prejudice against their social identity, for example their race, sex, or education level. When a healthcare provider discounts a woman's testimony about her symptoms because she is a woman, she is subject to epistemic injustice.

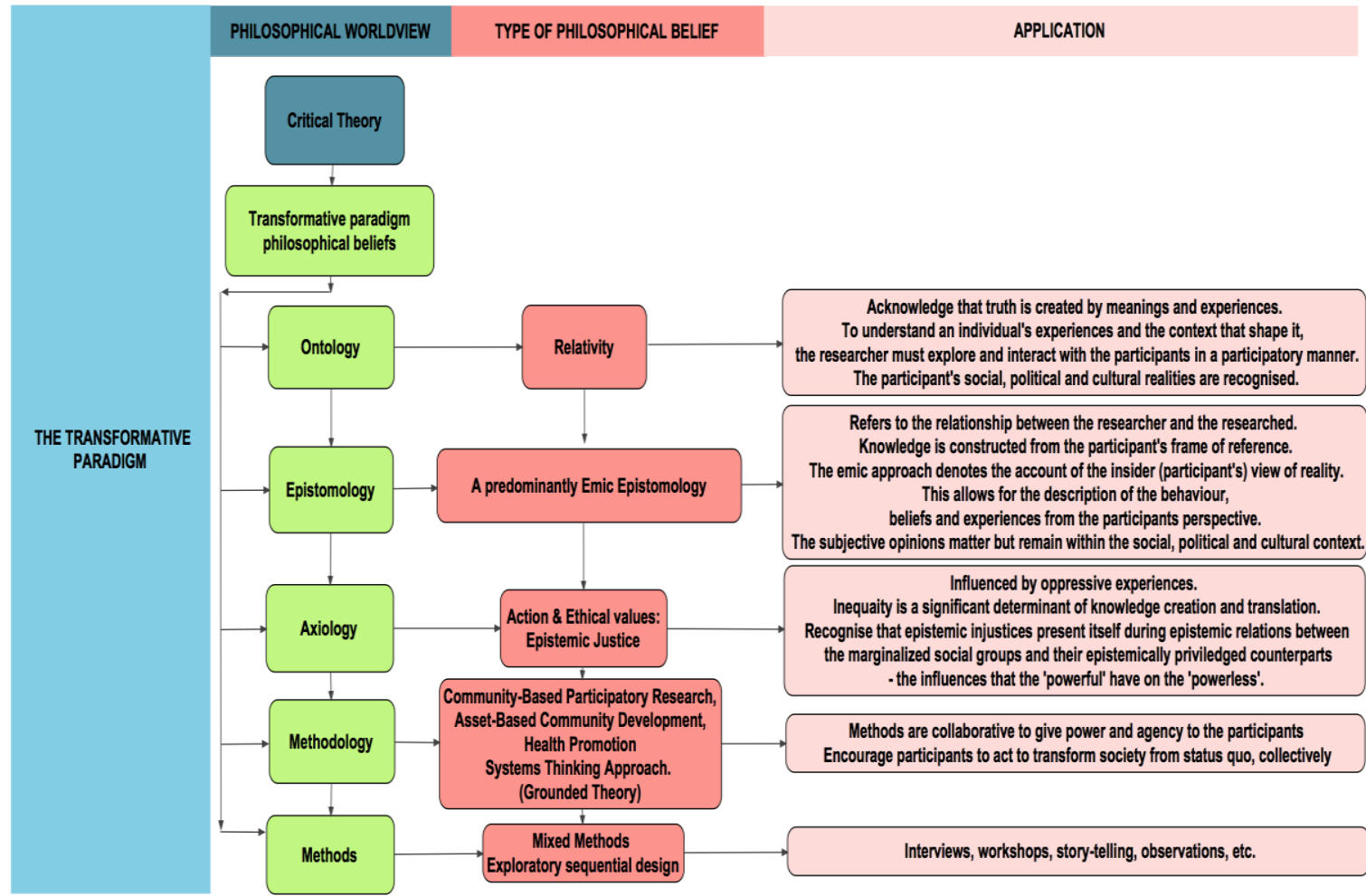

Figure 1. A conceptual model for the application of The Transformative Paradigm within a rural health development context, in South Africa.

Hermeneutical injustice occurs when an individual or social group lacks the interpretive resources to make sense of important features of a speaker's experience, because the marginalized group has been prejudicially excluded from meaning-making activities (Fricker 2007). When a marginalised group reports cultural reasons for non-adherence to a medication regime, hearers from dominant groups may fail to understand the experiences of that group, and the marginalized group will similarly struggle to explain their experience in terms which can easily be interpreted by dominant hearers. Inequality is a significant determinant in knowledge creation and translation. Epistemic injustices are present in epistemic relations between marginalized social groups and their epistemically privileged counterparts - they show themselves through the influences that the 'powerful' have on the 
'powerless' (Fricker, 2008) - prominent concepts throughout South Africa's history (Coovadia et al., 2009).

In the context of health care service delivery, healthcare providers are considered to have more health-related knowledge when compared to the patient, and so the patient truly has to trust the knowledge and expertise of the healthcare professional to obtain a favourable health outcome. With that stated, the healthcare professional also relies on the patient to provide him or her with the needed information about their physical health condition to make an accurate and comprehensive diagnosis. The majority of the uncertainty here is from the patient because he or she might lack the medical knowledge and skills to make informed decisions (Grünloh et al., 2018). It is therefore said that there is an asymmetrical knowledge relationship and principal-agent problem between healthcare providers and their patients (Ludwig et al., 2010; Nguyen, 2011; Sharma, 1997).

Epistemic injustices commonly occur in health care settings. Healthcare practitioners are often faced with finding the balance between epistemic objectification and epistemic shrinking (Carel \& Kidd, 2014; Haslanger, 2017; Kidd \& Carel, 2017; Persad, 2016). Epistemic objectification involves treating a patient as nothing more than a body of evidence - not having enough trust in the patient as a bearer of knowledge about their health or health care. Epistemic shrinking involves failure, by the healthcare practitioner, to assume expert responsibility for judgements made, placing too much trust in the patient as a bearer of knowledge about their health and health care. Healthcare practitioners therefore are obliged to balance the evidential stance and trusting stance.

The literature suggests that individuals may, through critical reflection, train themselves to facilitate epistemic justice (Anderson, 2012), through identifying and addressing various markers of false credibility, such as: (a) education (Fricker, 2007); and (b) ethnocentrism, where higher credibility is provided to the testimony of in-group members over out-group members (Brewer, 1999). It can also be done through shared reality bias, the tendency of individuals who interact frequently to converge in their perspectives on and judgements about the world (Curtis et al., 2001). Knowledge translation is complex, iterative, multidimensional, and non-linear, engaging multiple stakeholders. Engaged research can help steer the process (Roy \& Campbell, 2015). It is therefore crucial when performing engaged research projects, for effective health and knowledge transfer interventions within indigenous 
South African contexts, that tacit knowledge systems be acknowledged and epistemic justice be promoted.

\section{HEALTH PROMOTION}

Health promotion, within this context, relies on the engaged research concepts (CBPR, and epistemic justice) as the foundation to health development. It is an interdisciplinary science that draws from biological, environmental, psychological, physical, and medical sciences to promote health and to prevent diseases, disability, and premature death through educationdriven, voluntary behavior change activities (UGA, 2015). Health promotion is key to the growth of empowered individuals, groups, and a community through the use of systemic strategies to improve health knowledge, attitudes, skills, and behaviour (WHO, 2014). Factors identified to promote health and knowledge transfer may comprise of participant cognitive, dispositional, motivational, and ability characteristics and program design factors ideal for adult learning (Bates et al., 2000; Chiaburu et al., 2010; Keith \& Frese, 2008; Martin, 2010; Naquin \& Holton III, 2002; Sitzmann et al., 2010). It is important to focus on disease prevention through health promotion, as this reduces the cost that individuals, employees, families, communities, medical facilities, insurance companies, and the government incur on medical treatment as a consequence of non-communicable and communicable diseases.

The adoption of the 1978 Alma Ata Declaration facilitated health promotion awareness through striving towards 'Health for All' (WHO, 1978). It should, however, be recognised that efforts to commit to this declaration are yet to work effectively. To re-evaluate and improve on seven decades of attempts to commit to the 'Health for All' motto, the WHO has called world leaders again to "live up to the pledges and commit to concrete steps to advance \#HealthforAll" (Soroptimist International, 2018, para. 1) on the World Health Day, 7th of April 2018. The Alma Ata Declaration facilitated strategies for community participation, which are considered useful when implementing health promotion activities. With health promotion activities gaining momentum in South Africa since 1990, the focus on synergizing mechanisms for demonstrating evidence of health promotion effectiveness with regard to health, social, economic, and political impact are lacking. Health promotion education and training are needed (Onya, 2007).

Considering the epidemic rise in NCDs and the impact that it has on public health within South Africa, the focus should therefore not only be placed on disease treatment, but also on disease prevention, through supporting and strengthening public health promotion initiatives 
within the remote rural communities using a bottom-up approach propagated by The Alma Ata Declaration. Disease prevention, through health promotion strategies, aids the reduction of costs that individuals, employees, medical facilities, insurance companies and governments incur on medical treatment, because of NCDs.

\section{HEALTH LITERACY}

Health literacy refers to the cognitive and social skills which determine the motivation and the ability of individuals to gain access to, understand, and use information in ways which promote and maintain good health (WHO, 2016b). Health literacy consists of three discrete layers: (a) functional literacy; (b) conceptual literacy; and (c) health literacy as empowerment. Functional literacy consists of the skills that allow an individual to read, for example, consent forms and medicine labels, and to understand written and oral information given by pharmacists or other health professionals (Burgess \& Hamilton, 2011). Conceptual literacy consists of those skills and competencies that individuals develop over their lifetimes to allow them to seek out, comprehend, evaluate, and use health information to make informed choices. Health literacy as empowerment involves both strengthening active citizenship for health through understanding people's rights as patients and their ability to navigate through the healthcare system and acting individually or collectively to improve health through the political system by voting, advocacy, or membership of social movements (WHO, 2009).

When promoting health within rural communities and for people to be informed and to make well-informed health decisions, it is crucial that they are willing and able to learn from the health information presented. Their motivation, willingness and abilities are influenced by the perceived and actual difficulty of the presentation or text (Leroy et al., 2010). It is therefore essential to utilize methods to lower these barriers to improve the comprehension of health information. In SA, where two-thirds of the population cannot read basic health educational material, visual material and story-telling can be an effective tool in health promotion for lowliterates (Carstens et al., 2006). Story-telling is an effective approach to literacy development, specifically within the indigenous cultures of the Eastern Cape (Makaluza, 2018). Storytelling provides the platform for common cultural heritage which is considered to be the unifying force for indigenous cultures, in resisting the divisive efforts of the apartheid era (Smith, 2018). Furthermore, story-telling provided a wealth of role models and friends who lead the way through challenging situations and form an important part of human experience (Chapman, 1998). Story-telling therefore provides the ideal communication pathway when 
promoting health literacy within these contexts (Hardy, 2017; Neeley, 2016; Tsui \& Starecheski, 2018).

Health literacy requires researchers to focus on both visual and audible communication tools when promoting health within rural contexts. Using visuals as a communication tool for people with low literacy levels has proved to be effective in recalling previously communicated information (Houts et al., 1998; Houts et al., 2001; Houts et al., 2006). To facilitate visual processing, Leroy et al. (2010) propose that the focus be placed on the overall sentence structure, noun phrase complexity, and function word density to evaluate text difficulty. Corcoran and Ahmad (2015) recommend that the health information material should have reader-friendly cover graphics to attract attention and to illustrate the purpose of the information material. It is crucial to understand that images assist the reader to better understand and recall messages (Kondilis et al., 2010). Nonverbal communication such as facial expressions, head nods, and other body language may also have an effect on the way in which visual cues are processed. Nonverbal communication techniques should therefore be carefully considered when presenting audible health information to the listeners in person (Fontana et al., 2015).

The audible processing of health information could be enhanced by the addition of relatable and understandable visual cues (Möttönen et al., 2014; Paris et al., 2017). For the health information recipient to process audible information it has to be innocuous and in a language appropriate to the listener. To facilitate this, a translator is often used in cross-cultural qualitative research, but it is done with caution (Squires, 2009; Temple \& Edwards, 2002; Xian, 2008). Using repetition techniques for reinforcing the important health information communicated and through personalizing the presentation content, listener engagement may be facilitated (Covey, 2004). Visual and audible communication facilitators, such as storytelling, could ease content understanding by the health information recipient and should be considered when engaging with participants and promoting health in rural contexts.

Within the South African context, specifically, health literacy is a crucial determinant of health. The ability to read, interpret, and follow health instructions and health education materials is severely limited by the literacy level of the reader (Duxbury, 2019). This greatly affects those in the lower social-economic strata, as indicated in the 'Introduction and Context' section of this chapter. 


\section{RECOMMENDATIONS}

Within this context, instead of resorting to academic literature to identify a research problem, the researchers could employ a variety of qualitative and quantitative methods, inclusive of community member participation, to identify the focus of the research. This may be done through focus group discussions, interviews, and surveys, amongst others. Research should be integrated with previously held knowledge and new knowledge created through dynamic interactions between the stakeholders. It is imperative that researchers understand both indigenous and Western health knowledge and belief systems, commonly known as twoeyed seeing. By facilitating development through an asset-based approach that incorporates the concerns of epistemic justice, these variables can be understood by communities and thereafter harnessed and adapted for health empowerment. It is important to understand the systems operating within the indigenous community of interest. In addition, the analysis of community health variables through systems thinking allows researchers to capture the complexities involved in persistent complex health and social problems. These problems comprise a high level of interconnectedness and interdependence on various levels, which linear, chronological thinking alone cannot solve.

This chapter serves to illustrate an overarching depiction in which solutions to health challenges, which are rooted in socio-cultural and political conditions, seem unlikely to be addressed solely through bio-medical interventions. These health challenges could be improved through increasing the understanding in local communities of the risks and barriers for effective health and well-being, improved health literacy and relationships with health care workers, and effective, culturally relevant, epistemically just health promotion programs. As healthcare professionals, pharmacists play a role in identifying the factors that contribute to the complex health challenges in social, cultural, and behavioral contexts, to implement systematic and epistemically just health developmental activities accordingly. This understanding is critical for pharmacists and health care workers who require a more holistic understanding of the complex socio-cultural situations in which they are working and could aid in achieving a balance between epistemic shrinking and epistemic objectification.

The WHO emphasizes that in order to improve the effectiveness of the healthcare system and public health, pharmacists and fellow healthcare professionals have to engage in preventative care activities, services, and health empowerment. More socially responsible approaches, such as health promotion, have consequently been included as one of the six 
components which forms the underlying philosophy of Good Pharmacy Practice by the World Health Organization (WHO, 2012). The focus is therefore changing from a 'practitionercentred model' to a more 'patient-centred model' where the patient plays an active role in their health development and their healthcare opinions are valued and recognized. More research needs to be done on how healthcare practitioners, and pharmacists in particular, play this role and how thinking about these social aspects can inform healthcare practice.

\section{CONCLUSION}

Public health challenges are decidedly dependent on the knowledge, skills, and motivation of human resources for health. There is a need for successful, cost-effective, and epistemically just public health interventions that emphasise marginalized community participation in addressing their health challenges. Participatory research approaches focus on co-learning, applied knowledge production, and acknowledge the community as a unit of identity, solutions, and practice. These characteristics align with those of epistemic justice, which is to acknowledge, value, and involve prejudicially marginalized social groups as "knowers."

The transformative paradigm could be considered to be an innovative approach to health research, which aids in bridging the gap between science and practice through community engagement and social action to improve health equity. Consequently, this paradigm requires the researchers to recognize inequalities and injustices in society and poses a shared sense of responsibility. The researcher directly engages in working inclusively with the communities to challenge the present circumstances within and advance social justice and human rights. In indigenous contexts, the acknowledgement of tacit knowledge can lessen the colonial legacy of marginalization. Excluding or ignoring tacit knowledge could be reminiscent of colonial injustices where indigenous people were deprived not just of their knowledge and culture but also of their human identity and dignity.

Effective health promotion activities could be achieved through sensitive and contextual strategies. The adoption of such strategies could ultimately lead to populations practicing more healthy behaviors to reduce the epidemic effects of complex health. The environment for knowledge transfer to occur needs to be motivated. The impact that complex health challenges have on health and development requires immediate action and one of the measures that has shown to aid with this is health promotion. Within a culturally diverse country such as South Africa differences in education, social and cultural backgrounds are important concepts when disseminating health information and conducting health promotion 
activities. Failure to acknowledge these differences can create communication barriers between healthcare professionals and clients. Through an engaged research project, researchers can understand the variables that determine community health, such as culture, health literacy, and other socio-economic factors.

Acknowledgements. The authors would like to acknowledge the Rhodes University Faculty of Pharmacy, Rhodes University Community Engagement Office, the National Research Foundation and the Southern African Systems Analysis Centre for funding and supporting the research.

\section{REFERENCES}

Abel, R. (2015). Politics By Other Means: Law in the Struggle Against Apartheid, 1980-1994. Routledge.

Acharya, L. B., \& Cleland, J. (2000). Maternal and child health services in rural Nepal: Does access or quality matter more? Health Policy and Planning, 15(2), 223-229. https://doi.org/10.1093/heapol/15.2.223

ANC. (1997). ANC strategy and tactics by ANC 1997. In African National Congress. https://www.marxists.org/subject/africa/anc/1997/strategy-tactics.htm

Anderson, E. (2012). Epistemic justice as a virtue of social institutions. Social Epistemology, 26(2), 163-173. https://doi.org/10.1080/02691728.2011.652211

Armenakis, A., \& Kiefer, C. (2007). Social and cultural factors related to health. Global Health Education Consortium.

Armstrong, P., Erasmus, M., \& Rich, E. (2017). Benefit incidence, financing incidence and need of healthcare services in South Africa. https://www.datafirst.uct.ac.za/dataportal/index.php/catalog/451

Israel, B., Schulz, A. J., Parker, E. A., \& Becker, A. B. (1998). Review of community-based research: Assessing partnership approaches to improve public health. Annual Review of Public Health, 19(1), 173-202. https://doi.org/10.1146/annurev.publhealth.19.1.173

Bates, A., Holton, E. F., \& Carvalho, M. A. (2000). The role of interpersonal factors in the application of computerbased training in an industrial setting. Human Resource Development International, 3(1), 19-42. https://doi.org/10.1080/136788600361920

Boyd, C. P., Hayes, L., Wilson, R. L., \& Bearsley-Smith, C. (2008). Harnessing the social capital of rural communities for youth mental health: An asset-based community development framework. Australian Journal of Rural Health, 16(4), 189-193. https://doi.org/10.1111/j.1440-1584.2008.00996.x

Brewer, M. B. (1999). The psychology of prejudice: Ingroup love or outgroup hate? Journal of Social Issues, 55(3), 429-444. http://citeseerx.ist.psu.edu/viewdoc/download?doi=10.1.1.197.4614\&rep=rep1\&type=pdf

Burger, R., \& Christian, C. (2018). Access to health care in post-apartheid South Africa: Availability, affordability, acceptability. Health Economics, Policy and Law, 5(1), 43-55. https://doi.org/10.1017/S1744133118000300

Burgess, A., \& Hamilton, M. (2011). Back to the future? functional literacy and the new skills agenda. Amy Burgess and Mary Hamilton.

Carel, H., \& Kidd, I. (2014). Epistemic injustice in healthcare: A philosophical analysis. Medicine, health care, and philosophy, 17, 529-540. https://doi.org/10.1007/s11019-014-9560-2 
Carstens, A., Maes, A., \& Gangla-Birir, L. (2006). Understanding visuals in HIV/AIDS education in South Africa: Differences between literate and low-literate audiences. African Journal of AIDS Research, 5(3), 221-232. https://doi.org/10.2989/16085900609490383

Chapman, M. (1998). The problem of identity. New Literary History, 29(1), 85-99. https://www.jstor.org/stable/pdf/20057469.pdf?refreqid=excelsior\%3Ae274b2610a35a1ae43b23aa5b18663 cc

Chiaburu, D. S., Van Dam, K., \& Hutchins, H. M. (2010). Social support in the workplace and training transfer: A longitudinal analysis. International Journal of Selection and Assessment, 18(2), 187-200. https://doi.org/10.1111/j.1468-2389.2010.00500.x

Cleveland, M., Rojas-Méndez, J. I., Laroche, M., \& Papadopoulos, N. (2016). Identity, culture, dispositions and behavior: A cross-national examination of globalization and culture change. Journal of Business Research, 69(3), 1090-1102. https://doi.org/10.1016/j.jbusres.2015.08.025

Coovadia, H., Jewkes, R., Barron, P., Sanders, D., \& Mclntyre, D. (2009). The health and health system of South Africa: historical roots of current public health challenges. The Lancet, 374(9692), 817-834. https://doi.org/10.1016/S0140-6736(09)60951-X

Corcoran, N., \& Ahmad, F. (2015). The readability and suitability of sexual health promotion leaflets. Patient Education and Counseling, 99(2), 284-286. https://doi.org/10.1016/j.pec.2015.09.003

Covey, S. (2004). The 7 habits of highly effective people (15th ed.). Fireside Books, Simon \& Schuster, Free Press.

Cundill, G., Shackleton, S., Sisitka, L., Ntshudu, M., Lotz-Sisitka, H., Kulundu, I., \& Hamer, N. (2014). Social learning for adaptation: A descriptive handbook for practitioners and action researchers. Print Services Unit, Rhodes University.

Curtis, H., Conley, T. (2001). A relational approach to cognition: Shared experience and relationship affirmation in social cognition. In G. B. Moskowitz (Ed.) Cognitive social psychology: The Princeton symposium on the legacy and future of social cognition (pp. 3-17). Lawrence Erlbaum Associates.

Duxbury, T. O. (2019). Collaborative health literacy development: a World Health Organization workplace health promotion approach to address tobacco use. Rhodes University.

Duxbury, T., Rath, S., Maraj, P., Bosman, S. J., \& Srinivas, S. (2016). Controlling the use of tobacco for sustainable development: A focus on India and South Africa. Indian Journal of Pharmacy Practice, 9(2), 8694. https://doi.org/10.5530/ijopp.9.2.5

Fontana, P. C., Cohen, S. D., \& Wolvin, A. D. (2015). Understanding listening competency: A systematic review of research scales. International Journal of Listening, 29(3), 148-176. https://doi.org/10.1080/10904018.2015.1015226

Fricker, M. (2007). Epistemic injustice: power and the ethics of knowing. Oxford University Press. https://doi.org/10.1093/acprof:oso/9780198237907.001.0001

Fricker, M. (2008). Forum on Miranda Fricker's epistemic injustice: Power and the ethics of knowing précis. https://pdfs.semanticscholar.org/2d07/be741262b4afbac1be5bb6b2366c707af17c.pdf

Frost, L., Jenkins, L. S., \& Emmink, B. (2017). Improving access to health care in a rural regional hospital in South Africa: Why do patients miss their appointments? African Journal of Primary Health Care \& Family Medicine, 9(1), e1-e5. https://doi.org/10.4102/PHCFM.V9I1.1255

Grünloh, C., Myreteg, G., Cajander, Å., \& Rexhepi, H. (2018). "Why do they need to check me?" patient participation through ehealth and the doctor-patient relationship: A qualitative study. Journal of Medical Internet Research, 20(1), e11. https://doi.org/10.2196/jmir.8444 
Guba, E. G., \& Lincoln, Y. S. (1982). Epistemological and methodological bases of naturalistic inquiry. ECTJ, 30(4), 233-252. https://doi.org/10.1007/BF02765185

Guba, E. G., \& Lincoln, Y. S. (2005). Paradigmatic controversies, contradictions, and emerging confluences. In N. K. Denzin \& Y. S. Lincoln (Eds.), The Sage handbook of qualitative research (pp. 191-215). Sage.

Hardy, B. (2017). Telling stories that promote health transformation. Rethink Health. https://www.rethinkhealth.org/the-rethinkers-blog/telling-stories-that-promote-health-transformation/

Haslanger, S. (2017). Objectivity, epistemic objectification, and oppression. In Kidd, I. J., Medina, J. \& Pohlhaus, G. (Eds.), Routledge handbook on epistemic injustice (pp. 281-290). Taylor and Francis. https://doi.org/10.4324/9781315212043

Houts, P S, Bachrach, R., Witmer, J. T., Tringali, C. A., Bucher, J. A., \& Localio, R. A. (1998). Using pictographs to enhance recall of spoken medical instructions. Patient Education and Counseling, 35(2), 83-88. https://doi.org/10.1016/S0738-3991(98)00065-2

Houts, P S, Witmer, J. T., Egeth, H. E., Loscalzo, M. J., \& Zabora, J. R. (2001). Using pictographs to enhance recall of spoken medical instructions. Patient Education and Counseling, 43(3), 231-242. https://doi.org/10.1016/S0738-3991(00)00171-3

Houts, Peter S, Doak, C. C., Doak, L. G., \& Loscalzo, M. J. (2006). The role of pictures in improving health communication: A review of research on attention, comprehension, recall, and adherence. Patient Education and Counseling, 61(2), 173-190. https://doi.org/10.1016/j.pec.2005.05.004

Humanium. (2016). Right to health around the globe: together for children's rights. http://www.humanium.org/en/world/right-to-health/

International Monetary Fund. (2015). Causes and consequences of income inequality: A global perspective. https://www.imf.org/external/pubs/ft/sdn/2015/sdn1513.pdf

Israel, B. A., Schulz, A. J., Parker, E. A., Becker, \& B., A. (1998). Review of community-based research: assessing partnership approaches to improve public health. Annual Review of Public Health, 19(1), 173202. https://doi.org/10.1146/annurev.publhealth.19.1.173

Keith, N., \& Frese, M. (2008). Effectiveness of error management training: a meta-analysis. Journal of Applied Psychology, 93(1), 59-69. https://doi.org/10.1037/0021-9010.93.1.59

Kidd, I. J., \& Carel, H. (2017). Epistemic injustice and illness. Journal of Applied Philosophy, 34(2), 172-190. https://doi.org/10.1111/japp.12172

Kondilis, B., Akrivos, P., Sardi, T., Soteriades, E., \& Falagas, M. (2010). Readability levels of health pamphlets distributed in hospitals and health centres in Athens, Greece. Public Health, 124, 547-552. https://doi.org/ 10.1016/j.puhe.2010.05.010

Lazarus, S., Naidoo, A., May, B., Williams, L., Demas, G., \& Filander, F. (2014). Lessons learnt from a community-based participatory research project in a South African rural context. South African Journal of Psychology, 44(2), 149-161. https://journals.sagepub.com/doi/pdf/10.1177/0081246314528156

Leroy, G., Helmreich, S., \& Cowie, J. R. (2010). The influence of text characteristics on perceived and actual difficulty of health information. International Journal of Medical Informatics 79(6), 438-449. https://doi.org/10.1016/j.ijmedinf.2010.02.002

Li, J., \& Karakowsky, L. (2001). Do we see eye-to-eye? Implications of cultural differences for cross-cultural management research and practice. The Journal of Psychology, 135(5), 501-517. https://doi.org/10.1080/00223980109603715 
Lie, D., Carter-Pokras, O., Braun, B., \& Coleman, C. (2012). What do health literacy and cultural competence have in common? Calling for a collaborative health professional pedagogy. J Health Commun, 17(3), 1322. https://doi.org/10.1080/10810730.2012.712625

Ludwig, M., Van Merode, F., \& Groot, W. (2010). Principal agent relationships and the efficiency of hospitals. The European Journal of Health Economics, 11(3), 291-304. https://doi.org/10.1007/s10198-009-0176-Z

Mairhofer, S. (2015). Community-based participatory health research: Promoting health equity in communities. Procedia - Social and Behavioral Sciences, 197, 382-387. https://doi.org/10.1016/j.sbspro.2015.07.153

Makaluza, N. (2018). Storytelling for early literacy development in isiXhosa: a case study of a grad one class in the Western Cape [Unpublished master's thesis]. University of the Western Cape. http://etd.uwc.ac.za/xmlui/handle/11394/5853

Makana Municipality. (2017). Makana local municipality: Socio-economic review and outlook. www.ecsecc.org.

Manhanzva, R., Marara, P., Duxbury, T., Bobbins, A. C., Pearse, N., Hoel, E., Mzizi, T., \& Srinivas, S. C. (2017). Gender and leadership for health literacy to combat the epidemic rise of noncommunicable diseases. Health Care for Women International, 38(8), 833-847. https://doi.org/10.1080/07399332.2017.1332062

Martin, H. J. (2010). Workplace climate and peer support as determinants of training transfer. Human Resource Development Quarterly, 21(1), 87-104. https://doi.org/10.1002/hrdq.20038

Matebeni, F. (2018). Measuring rural household food security in the Nkonkobe local municipality, Eastern Cape Province of South Africa [Unpublished doctoral dissertation]. Stellenbosch University. https://scholar.sun.ac.za/handle/10019.1/103497

McIntyre, D., Ataguba, J. (2014). Access to quality health care in South Africa: Is the health sector contributing to addressing the inequality challenge? University of Cape Town. https://www.parliament.gov.za/storage/app/media/Pages/2017/october/High_Level_Panel/Commissioned_r eports_for_triple_challenges_of_poverty_unemployment_and_inequality/Diagnostic_Report_on_Access_to _Quality_Healthcare.pdf

McLaren, Z., Ardington, C., Leibbrandt, M. V. (2013). Distance as a barrier to health care access in South Africa [Working paper]. http://www.opensaldru.uct.ac.za/handle/11090/613

Mertens, D. M.(2009). Transformative Research and Evaluation. Guilford Press.

Mertens, D. M. (2005). Research and evaluation in education and psychology: integrating diversity with quantitative, qualitative, and mixed methods. Sage. https://eric.ed.gov/?id=ED500340

Mertens, D. M. (2007). Transformative paradigm: Mixed methods and social justice.

Journal of Mixed Methods Research, 1(3), 212-225. https://doi.org/10.1177/1558689807302811

Mertens, D. M. (2010). Philosophy in mixed methods teaching: The transformative paradigm as illustration. International Journal of Multiple Research Approaches, 4(1), 9-18. https://doi.org/10.5172/mra.2010.4.1.009

Mosavel, M., Simon, C., van Stade,D., \& Buchbinder, M. (2005). Community-based participatory research (CBPR) in South Africa: Engaging multiple constituents to shape the research question. Social Science Medicine, 61(12), 2577-2587. https://www.ncbi.nlm.nih.gov/pmc/articles/PMC3248692/

Möttönen, R., van de Ven, G. M., \& Watkins, K. E. (2014). Attention fine-tunes auditory-motor processing of speech sounds. The Journal of Neuroscience, 34(11), 4064-4069. https://doi.org/10.1523/JNEUROSCI.2214-13.2014

Murphy, P., \& Ivinson, G. (2003). Pedagogy and cultural knowledge: a sociocultural perspective. Pedagogy, Culture, and Society, 11(1), 5-9. https://doi.org/10.1080/14681360300200157 
Naquin, S. S., \& Holton III, E. F. (2002). The effects of personality, affectivity, and work commitment on motivation to improve work through learning. Human Resource Development Quarterly, 13(4), 357-376.

https://doi.org/10.1002/hrdq.1038

Neeley, L. (2016). The value of storytelling in public health and medicine. https://www.isr.umich.edu/cps/events/Neely_20160613.pdf

$\mathrm{Nel}, \mathrm{H}$. (2018). A comparison between the asset-oriented and needs-based community development approaches in terms of systems changes. Practice, 30(1), 33-52. https://doi.org/10.1080/09503153.2017.1360474

Nguyen, H. (2011). The principal-agent problems in health care: evidence from prescribing patterns of private providers in Vietnam. Health Policy and Planning, 26(1), i53-i62. https://doi.org/10.1093/heapol/czr028

Onya, H. (2007). Health promotion in South Africa. Promotion \& Education, 14(4), $233-237$. https://doi.org/10.1177/10253823070140041001

PAHO WHO. (2019). Annual report of the director. PAHO WHO. https://www.paho.org/annual-report-of-thedirector-2019/en/

Paris, T., Kim, J., \& Davis, C. (2017). Visual form predictions facilitate auditory processing at the N1. Neuroscience, 343, 157-164. https://doi.org/10.1016/j.neuroscience.2016.09.023

Persad, G. (2016). What Is the relevance of procedural fairness to making determinations about medical evidence? AMA Journal of Ethics, 19(2), 183-191. https://doi.org/10.1001/journalofethics.2017.19.2.pfor11702.

Peters, D. H., Garg, A., Bloom, G., Walker, D. G., Brieger, W. R., \& Hafizur Rahman, M. (2008). Poverty and access to health care in developing countries. Annals of the New York Academy of Sciences, 1136(1), 161171. https://doi.org/10.1196/annals.1425.011

Pfizer, Doak, L., \& Doak, C. (2004). Principles for clear health communication (2nd ed.). Pfizer Inc.

Results for Development Institute, World Bank. (2014). How to close the gap on MDGs 4 \& 5 in Africa: Evidence to inform policy options. http://www.r4d.org/sites/resultsfordevelopment.org/files/resources/How to close the gap on MDGs 4-5.pdf

Rodrigo, M., \& Andrés, F. (2010). Social and economic impact of illiteracy: Analytical model and pilot study. UNESCO. https://unesdoc.unesco.org/ark:/48223/pf0000190571

Rogers, E., Hart, B., \& Miike, Y. (2002). Edward T. Hall and the history of intercultural communication: The United States and Japan. Keto Communication Review, 3-26. http://www.mediacom.keio.ac.jp/publication/pdf2002/review24/2.pdf

Roy, S., \& Campbell, B. (2015). An indigenous epistemological approach to promote health through effective knowledge translation. Journal of Indigenous Research, 4(2015), 1-10. http://digitalcommons.usu.edu/kicjirhttp://digitalcommons.usu.edu/kicjir/vol4/iss2015/2

Seiber, E. E., \& Bertrand, J. T. (2002). Access as a factor in differential contraceptive use between Mayans and ladinos in Guatemala. Health Policy and Planning, 17(2), 167-177. https://doi.org/10.1093/heapol/17.2.167

Sharma, A. (1997). Professional as agent: knowledge asymmetry in agency exchange. The Academy of Management Review, 22(3), 758. https://doi.org/10.2307/259412

Sheridan, S. L., Halpern, D. J., Viera, A. J., Berkman, N. D., Donahue, K. E., \& Crotty, K. (2011). Interventions for individuals with low health literacy: a systematic review. J Health Commun, 16(3), 30-54. https://doi.org/10.1080/10810730.2011.604391 
Sitzmann, T., Ely, K., Brown, K., \& Kristina Bauer. (2010). Self-assessment of knowledge: A cognitive learning or affective measure? Academy of Management Learning \& Education, 9(2), 169 -191. https://doi.org/10.5465/amle.9.2.zqr169

Smith, C. (2018). Telling stories: Past and present heroes. Brigham Young University: Kenedy Center. http://kennedy.byu.edu/telling-stories-past-and-present-heroes/

Soroptimist International. (2018). World Health Day. https://www.soroptimistinternational.org/events/world-healthday-2/\#HealthForAll

South African Human Rights Commission. (2000). Right to Health. South African Human Rights Commision. http://www.sahrc.org.za/home/21/files/Reports/5th_esr_health.pdf

Statistics South Africa. (2019). Quarterly Labour Force Survey. http://www.statssa.gov.za/publications/P0211/P02111stQuarter2019.pdf

Squires, A. (2009). Methodological challenges in cross-language qualitative research: A research review. International Journal of Nursing Studies, 46(2), 277-287. https://doi.org/10.1016/j.jjnurstu.2008.08.006

Tanser, F., Gijsbertsen, B., \& Herbst, K. (2006). Modelling and understanding primary health care accessibility and utilization in rural South Africa: An exploration using a geographical information system. Social Science \& Medicine, 63(3), 691-705. https://doi.org/10.1016/j.socscimed.2006.01.015

Temple, B., \& Edwards, R. (2002). Interpreters/translators and cross-language research: reflexivity and border crossings. International Journal of Qualitative Methods, 1(2), 1-12. https://doi.org/10.1177/160940690200100201

The Department of Economic Development, E. A. and tourism. (2017). The Eastern Cape socio-economic review and outlook. http://www.ecdc.co.za/media/3749/dedeat-sero-report-2017_digital-version.pdf

Tsui, E. K., \& Starecheski, A. (2018). Uses of oral history and digital storytelling in public health research and practice. Public Health, 154, 24-30. https://doi.org/10.1016/j.puhe.2017.10.008

Türmen, T., Troedsson, H., \& Stahlhöfer, M. (2001). A human rights approach to public health: WHO capacity building in the area of children's rights. Health and Human Rights, 5(2), 147-154. https://doi.org/10.2307/4065368

Ubunye Foundation. (2018). Ubunye Foundation. http://www.ubunyefoundation.co.za/about-us.htm

UFNPA. (2004). Guide to working from within: 24 tips for culture sensitive programming. https://www.unfpa.org/sites/default/files/pub-pdf/24tips_eng.pdf.

UGA. (2015). What is health promotion \& behavior?. https://publichealth.uga.edu/departments/health-promotionbehavior/what-is-health-promotion/

Van den Broek, N. R., White, S. A., Ntonya, C., Ngwale, M., Cullinan, T. R., Molyneux, M. E., \& Neilson, J. P. (2003). Reproductive health in rural Malawi: a population-based survey. BJOG: An International Journal of Obstetrics and Gynaecology, 110(10), 902-908. http://www.ncbi.nlm.nih.gov/pubmed/14550359

Van de Venter, E., \& Redwood, S. (2016). Does an asset-based community development project promote health and wellbeing? The Lancet, 388(S108), 108. https://doi.org/10.1016/S0140-6736(16)32344-3 https://www.thelancet.com/journals/lancet/article/PIIS0140-6736(16)32344-3/fulltext

WHO. (1978). Declaration of alma ata. http://www.who.int/publications/almaata_declaration_en.pdf

WHO. (2009). Health literacy. http://www.who.int/healthpromotion/conferences/7gchp/Track1_Inner.pdf

WHO. (2011). Child mortality. http://www.who.int/pmnch/media/press_materials/fs/fs_mdg4_childmortality/en/ 
WHO. (2012). Joint FiPMHo guidelines on good pharmacy practice: standards for quality of pharmacy services. https://www.fip.org/www/uploads/database_file.php?id=331\&table_id=

WHO. (2013). Global action plan for the prevention and control of non-communicable diseases, 2013-2020. http://apps.who.int/iris/bitstream/10665/94384/1/9789241506236_eng.pdf

WHO. (2014). Milestones in health promotion. http://www.who.int/healthpromotion/milestones.pdf

WHO. (2015a). South Africa health expenditure. http://www.who.int/countries/zaf/en/

WHO. (2015b). Towards a monitoring framework with targets and indicators for the health goals of the post-2015 sustainable development goals.

http://www.who.int/healthinfo/indicators/hsi_indicators_sdg_targetindicators_draft.pdf

WHO. (2016a). NCDs, poverty and development. http://www.who.int/global-coordination-mechanism/ncdthemes/poverty-development/en/

WHO. (2016b). Health literacy and health behaviour.

http://www.who.int/healthpromotion/conferences/7gchp/track2/en/

World Economic Forum. (2016). Global gender gap report, 2016. World Economic Forum. https://reliefweb.int/sites/reliefweb.int/files/resources/WEF_Global_Gender_Gap_Report_2016.pdf

Xian, H. (2008). Lost in translation? Language, culture and the roles of translator in cross- cultural management research. Qualitative Research in Organization \& Management, 3(3), 231-245. https://doi.org/10.1108/17465640810920304 